\title{
My Kurdish Identity
}

\author{
Sumaya Muhamed ${ }^{1}$
}

King High School, Nashville, TN, USA

\begin{abstract}
This is a biographical, historical, and transnational poem about desiring the future. In the process, the experiences of Kurds in Nashville, TN is articulated in order to challenge simplistic renditions of Kurds in the United States. The poem offers a powerful version of the future.
\end{abstract}

Keywords: Kurdish identity, diaspora, Kurds, and Nashville.

When you look at me, what do you see?

Someone Turkish, Arab, or Indian, or someone who I wasn't meant to be?

But no, my heritage comes from this mystical land

A land my parents call Kurdistan

But if you ask me

I am from the bright lights of downtown

From crowded streets and old country guitars

I am from hey all around those music city folks

From Southern tip of Nashville Tennessee

I am American born but with a strong Kurdish heart

They say you can breathe in the fresh mountain air with the scent of sweet wildflowers

These same mountains that stood with such great power

So secretively hidden Noah's arc

As some say, among the arc were Goody

Which comes a nation called Kurdi

With valleys that stretch out as far as I can see

Housing people for thousands of years

Yearning for its inhabitants to be free

Of mankind's fascist cruelty

I wish that everyone would understand

That I am a Kurd without a homeland

A land in which I have not seen

But you'll see, my generation will be the one who'll set it free.

${ }^{1}$ Correspondence; E-mail; suadabdulla94@gmail.com 